\title{
Correction to: Geotechnics for Sustainable Infrastructure Development
}

\author{
Phung Duc Long and Nguyen Tien Dung
}

\section{Correction to: \\ P. Duc Long and N. T. Dung (eds.), Geotechnics for Sustainable Infrastructure Development, Lecture Notes in Civil Engineering 62, https://doi.org/10.1007/978-981-15-2184-3}

(1) In Chapter 42, the affiliation of Prof. Nguyen Hong Nam has been published as "Thuy Loi University". The correct affiliation is "Thuyloi University".

(2) In Chapter 70, the title of the right most column in table 5 has been published as "Con. Time (\%)". The correct title is "Con. time $(\mathrm{min} / \mathrm{m})$ ".

(3) In Chapter 74, the chapter title was published as "Aanalytical and numerical analyses on stiffness enhancement of ground improved by head-enlarged CDM columns". The correct chapter title is "Analytical and numerical analyses on stiffness enhancement of ground improved by head-enlarged CDM columns".

(4) Chapter 135 was published with missing figures-figures 8, 9, 10 and 11. Please find the missing figures below:

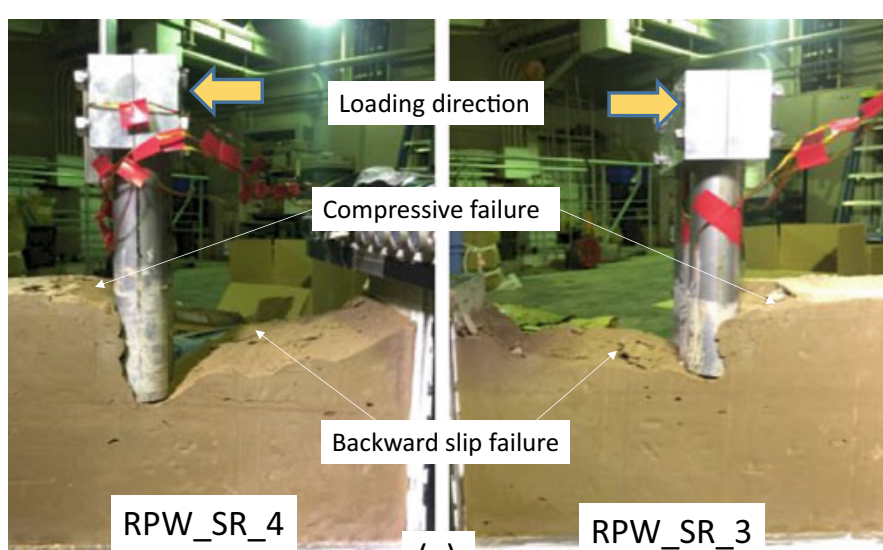

(a)

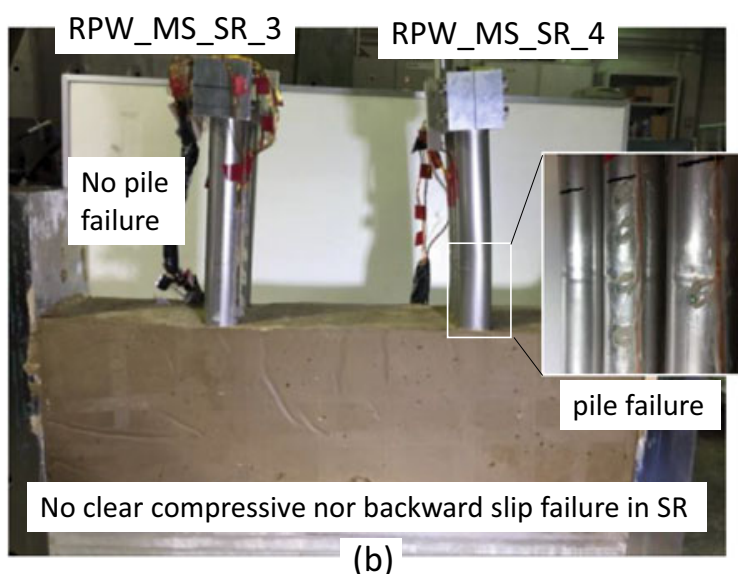

(b)

Figure 8. Failures of soft rock and tubular pile walls embedded in (a) SR layer and (b) MS/SR layer

The original versions of these chapters can be found at https://doi.org/10.1007/978-981-15-2184-3_42 https://doi.org/10.1007/978-981-15-2184-3_70 https://doi.org/10.1007/978-981-15-2184-3_74 https://doi.org/10.1007/978-981-15-2184-3_135 https://doi.org/10.1007/978-981-15-2184-3 


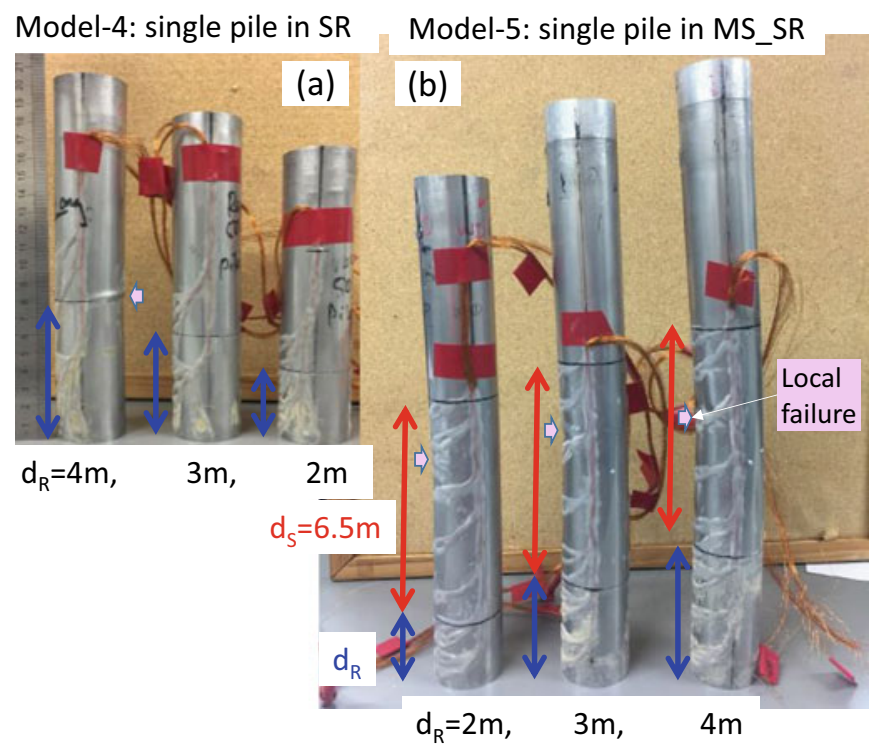

Figure 9. Failures of deformation of single pile embedded in (a) SR layer and (b) MS/SR layer

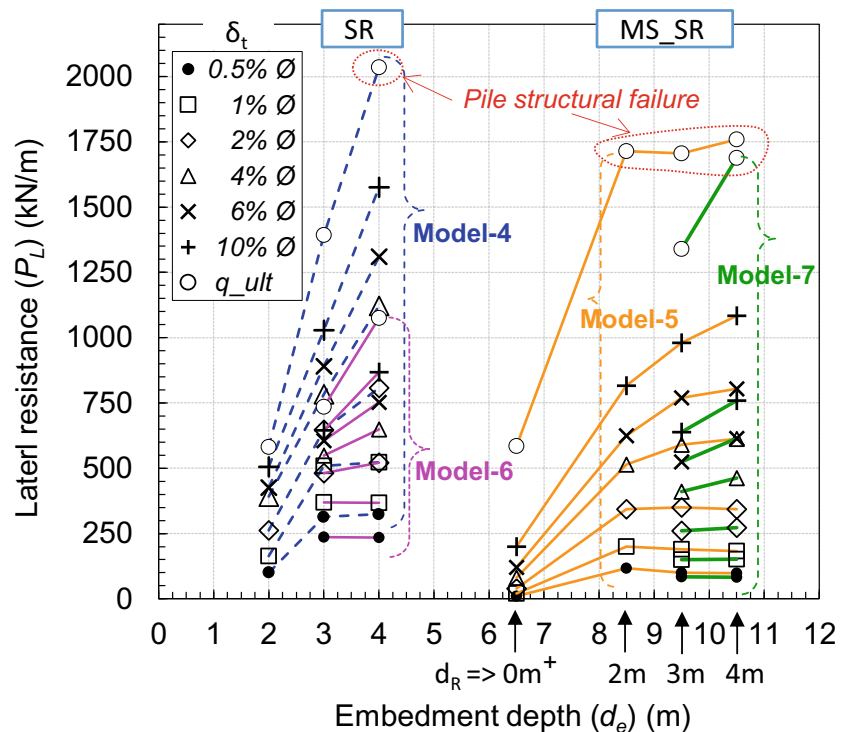

Figure 10. Lateral resistance of the walls and the piles 


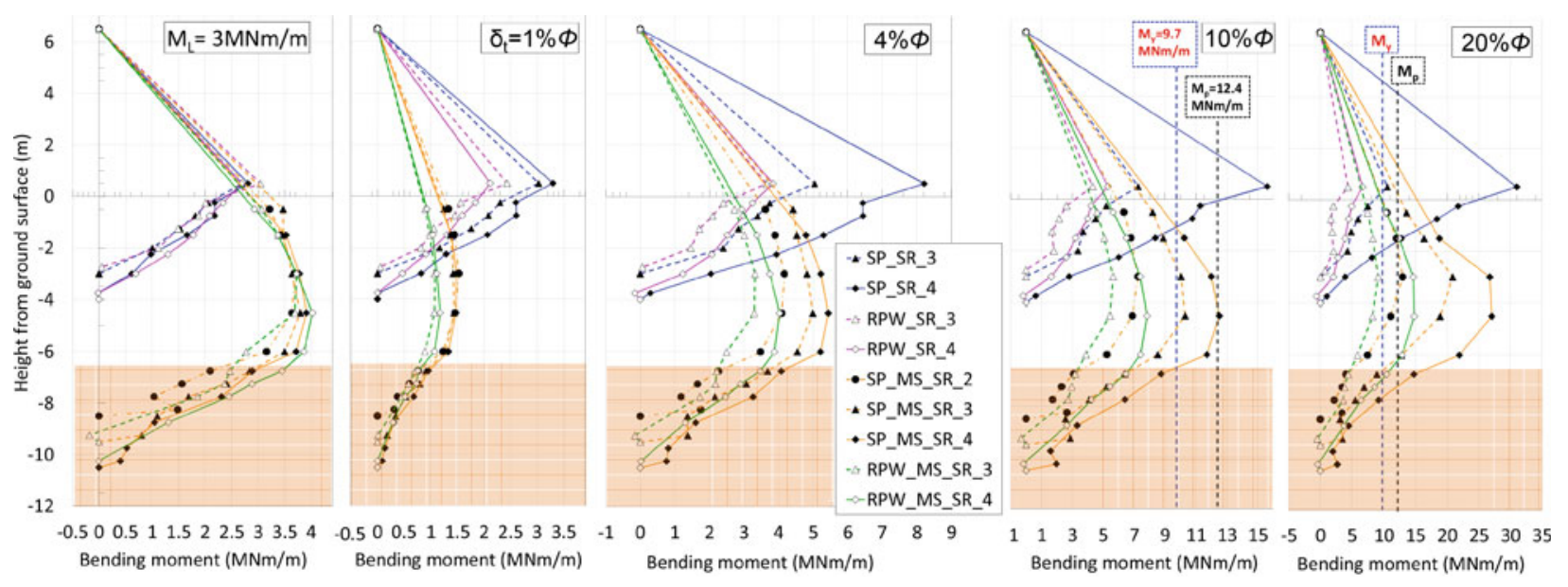

Figure 11. Nominal bending moments evaluated from strain gauge measurement 